\title{
Draining woofs
}

Tramas escorridas

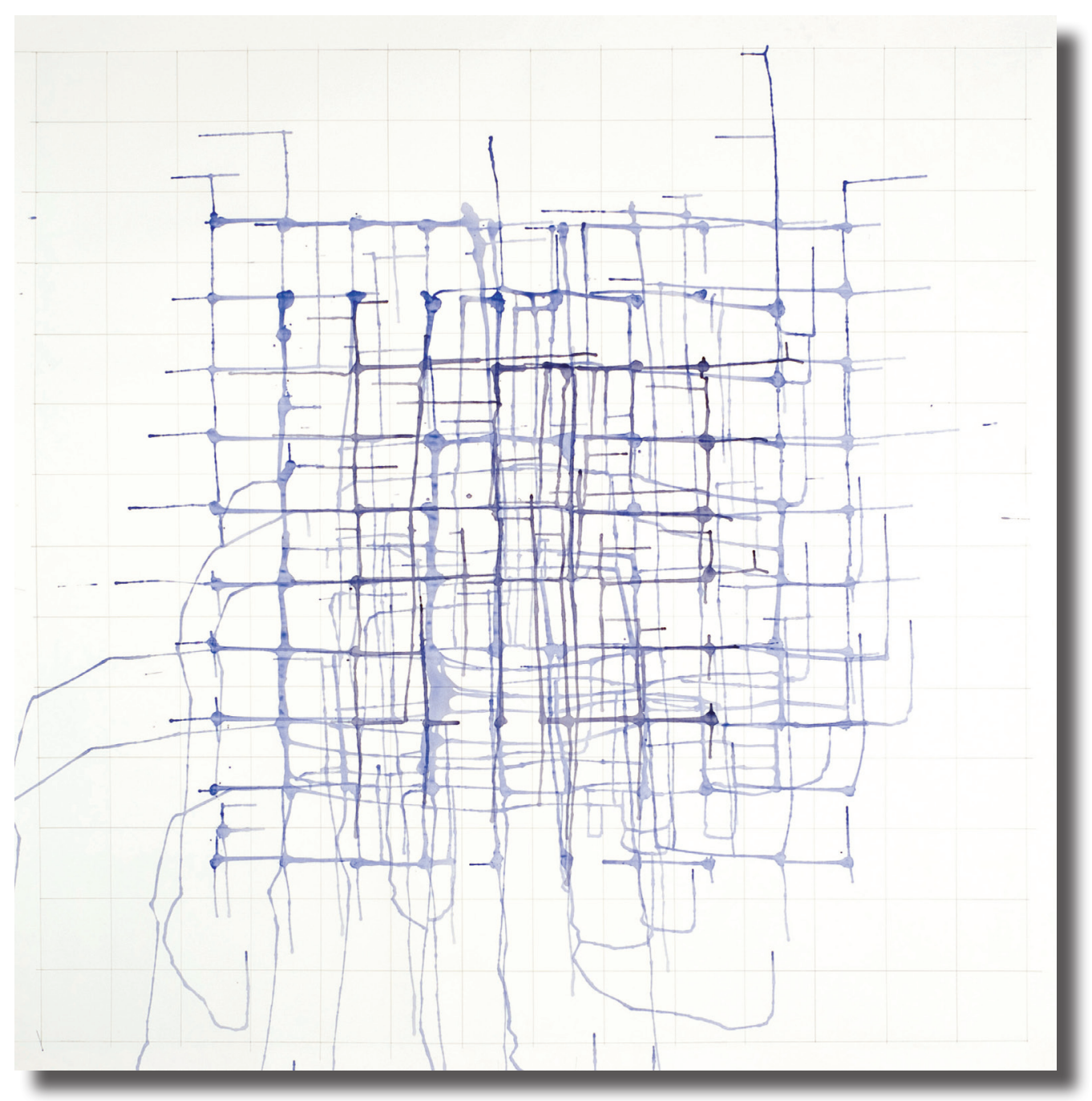

Gisela Waetge, Tramas Escorridas (Draining Woofs), 2007, painting and drawing on paper, acrylic, pigments, and graphite on paper, $1.35 \times 1.35 \mathrm{~m}$.

Photograph by Fábio del Re.

The Draining Woofs (Tramas Escorridas) are combined drawings/paintings or paintings/drawings. They are abstract and geometric pieces that allow several different associations. The superposed layers remind us of the pulse of a city, in an interwoven weft resembling the structures of our brain or a computer plate. The orthogonal mesh, the randomly draining dots, the lines and colors establish a game, a rhythm that can irradiate energy, light, or silence, and provoke reflections on time, measures, order, precision, and the very state and place of the art. (Gisela Waetge, during the exhibit Tripé/Paralelo 30, SESC Pompeia, São Paulo, Brazil, September 2010)

Texto e imagem fornecidos por Otto Sulzbach e Arte\&Fato Galeria. 